\title{
Systemic Juvenile Idiopathic Arthritis Mimicking Multisystem Inflammatory Syndrome in Children
}

\author{
Harshita Jagwani ${ }^{1} \cdot$ Priyankar Pal $^{1}$ (D) $\cdot$ Apurba Ghosh $^{1} \cdot$ Hriday De $^{1} \cdot$ Nupur Ganguly $^{1} \cdot$ Anurag Mondal $^{1}$. \\ Mohini Bhelo ${ }^{1}$
}

Received: 20 September 2021 / Accepted: 12 November 2021 /Published online: 7 January 2022

(c) Dr. K C Chaudhuri Foundation 2021

To the Editor: An 11-mo-old male child presented with a history of fever for $14 \mathrm{~d}$. On examination, the baby looked toxic with an erythematous rash over whole body and hepatomegaly. His father had recovered from SARS-CoV-2 infection two months back. Investigations showed $\mathrm{Hb}-8.3 \mathrm{~g} /$ $\mathrm{dL}$, WBC count $-34,660$ cells/cmm with $61 \%$ neutrophils, platelets $6.16 \mathrm{lakh} / \mathrm{cmm}, \mathrm{CRP}-80.8 \mathrm{mg} / \mathrm{L}$. His SAR-CoV-2 antibody titers were elevated $(850 \mathrm{AU} / \mathrm{mL})$; echocardiogram showed dilated left main coronary artery $(z$ score +2.29$)$. In view of contact history, clinical features, and increased inflammatory markers, he was provisionally diagnosed as multisystem inflammatory syndrome in children (MIS-C) and IV immunoglobulin $2 \mathrm{~g} / \mathrm{kg}$ was started followed by methylprednisolone $(10 \mathrm{mg} / \mathrm{kg})$ for $3 \mathrm{~d}$ following which, fever subsided. Oral prednisolone $2 \mathrm{mg} / \mathrm{kg} / \mathrm{d}$ was initiated, but within $2 \mathrm{~d}$, fever recurred along with evanescent, erythematous rashes. Repeat investigations showed WBC - 29,840 cells/cmm with $87 \%$ neutrophils, platelets $-6.66 \mathrm{lakh} / \mathrm{cmm}$, CRP - $169.3 \mathrm{mg} / \mathrm{L}$. On retrospective questioning, the mother informed that rashes were evanescent since onset of fever. The diagnosis was revised to systemic onset juvenile idiopathic arthritis (SJIA). Methylprednisolone $(30 \mathrm{mg} / \mathrm{kg}$ ) for $5 \mathrm{~d}$ was restarted followed by oral prednisolone. Fever subsided but reappeared within $2 \mathrm{~d}$ of oral therapy. Finally, subcutaneous tocilizumab was initiated following which, fever subsided with normalization of inflammatory markers.

Both SJIA and MIS-C present with fever, rashes, and elevated inflammatory markers. SJIA rash has been described as salmon pink in color, morbilliform, macular, often with central clearing which tends to be characteristically evanescent appearing during acute febrile episodes [1]. MIS-C rashes are fixed rashes varying from polymorphic, maculopapular, morbilliform to diffuse erythroderma [2]. Coronary dilatation is common in MIS-C. In SJIA, pancarditis can occur and coronary dilatations have been reported $[3,4]$.

With the ongoing pandemic, it is important to remember that all febrile children with elevated inflammatory markers and COVID IgG positivity are not necessarily MIS-C.

\section{Declarations}

Conflict of Interest None.

\section{References}

1. Bywaters EG, Isdale IC. The rash of rheumatoid arthritis and Still's disease. Q J Med. 1956;25:377-87.

2. Whittaker E, Bamford A, Kenny J, et al. Clinical characteristics of 58 children with a pediatric inflammatory multisystem syndrome temporally associated with SARS-CoV-2. JAMA. 2020;324:259-69.

3. Binstadt BA, Levine JC, Nigrovic PA, et al. Coronary artery dilation among patients presenting with systemic-onset juvenile idiopathic arthritis. Pediatrics. 2005;116:e89-93.

4. Lefèvre-Utile A, Galeotti C, Koné-Paut I. Coronary artery abnormalities in children with systemic-onset juvenile idiopathic arthritis. Joint Bone Spine. 2014;81:257-9.

Publisher's Note Springer Nature remains neutral with regard to jurisdictional claims in published maps and institutional affiliations.

Priyankar Pal

mailme.priyankar@gmail.com

1 Department of Pediatrics, Institute of Child Health, Kolkata, West Bengal 700017, India 